\title{
FUNCTIE EN TAAK VAN DE (RIJKS)ACCOUNTANT
}

\author{
door P. Wisse
}

Een accountant is een deskundige op het gebied van de administratieve controle, de administratieve organisatie en de bedrijfseconomie.

Hij kan optreden in een controlerende- en in een adviserende functie.

De controlerende functie omvat het instellen van een onderzoek in of door middel van een administratie naar de juistheid van gegevens, welke betrekking hebben op het economisch gebeuren in een huishouding.

De controle heeft een retrospectief karakter en zal in de regel décharge van een beheer of constatering van feiten ten doel hebben.

Te onderscheiden zijn:

\section{Algemene controle}

- In beginsel meermalige controle van verantwoordingsstukken, in het bijzonder van jaarrekeningen en/of tussentijdse balansen en resultatenrekeningen.

- Eenmalige enkele balanscontrole.

Controle met bijzonder doel

- In beginsel meermalige controle op de naleving van wettelijke bepalingen (bv. belastingen, economische voorschriften), eenzijdige regelingen (bv. subsidies), overeenkomsten (bv. kartels, kredieten) e.d.

- Eenmalige controle van een administratie (bv. bij faillissement of fraude) of van administratieve gegevens (bv. regie-afrekening, schaderekening, kostprijsberekening, hoogte van de oplaag, hoogte van de omzet).

De adviserende functie omvat het uitbrengen van adviezen op het gebied van de administratieve organisatic (waaronder de interne controle) en de bedrijfseconomie (veaagstukken van waarde en winst, kostprijs, financiering, e.d.). De adviezen zullen in de regel worden gegeven ter voorbereiding van beleidsbeslissingen en zullen dus meestal een prospectief karakter dragen.

De adviserende functie is dikwijls aan de controlerende functie verbonden, in die zin dat bij de controlewerkzaamheden feiten of omstandigheden kunnen blijken welke aanleiding geven tot het verstrekken van een ongevraagd advies. Het gevraagde advies kan een algemeen of een bijzonder karakter dragen. In het eerste geval wordt het advies gebaseerd op de vakkennis die de accountant heeft of zich alsnog verwerft. In het tweede geval wordt het advies gebaseerd op specifieke gegevens, welke uiteraard vakkundig moeten worden verwerkt, en waarvan de bruikbaarheid voor dit doel moet worden vastgesteld.

De specifieke onderzoeken ten behoeve van cen advies (investigations) zijn naar hun aard eenmalig en prospectief gericht. Zij kunnen betrekking hebben op een te sluiten ondernemersovereenkomst, waarde van een onderneming, kredietwaardigheid, levensvatbaarheid (surséance), subsidiebehoefte e.d. en voorts op allerlei onderwerpen van bestuursbeleid. 
In de hierboven gemaakte onderscheiding eindigen de controles met bijzonder doel met een verklaring (van juistheid of niet-gebleken-onjuistheid) en de investigations met een advies.

In sommige gevallen wordt de genoemde verklaring vervangen door een advies (bv. aanslag op te leggen of schadevergoeding te regelen naar cen bepaald bedrag). Dit is wellicht te verklaren doordat de controle vaak aanleiding geeft tot correcties en van de betrokkene niet het overleggen van een gecorrigeerd stuk wordt geeist (nog daargelaten de vraag of deze wel met de correcties akkoord gaat). Het controlekarakter wordt er niet door aangetast. Zelfs het certificaat onder de jaarrekening zou kunnen worden vervangen door een advies om de jaarrekening goed te keuren en aan de directie décharge te verlenen. Het is echter niet doelmatig, om die reden de controle van de jaarrekening tot de adviserende functie te rekenen.

Gaan we thans na, wie bij het fungeren van de accountant betrokken zijn dan kunnen we onderscheiden:

- degene die de opdracht tot controle verstrekt of het advies vraagt (de opdrachtgever);

- degene wiens administratie wordt gecontroleerd of als basis dient voor het advies (de gecontroleerde);

- degene te wiens behoeve de controle wordt verricht of aan wie het advies wordt verstrekt (de belanghebbende).

De opdrachtgever kan zijn een natuurlijk- of rechtspersoon of (in een andere onderscheiding) particulier dan wel leider of leidend orgaan van een huishouding. Belanghebbende kan iedereen zijn. Er zijn twee groepen van belanghebbenden te onderscheiden, $\mathrm{nl}$. degenen die zelf opdrachten kunnen verstrekken en degenen die daartoe niet in staat zijn.

Tot de eerste groep behoren behalve de opdrachtgevers ook andere met hen verbonden geïnteresseerden, die tezamen cen beperkte kring vormen, aan te duiden als gesloten verkeer.

De tweede groep kan worden angeduid als het maatschappelijk verkeer. Hiertoe behoren:

- degenen die belang hebben bij de grootte van het vermogen en/of de winst van de bedrijfshuishouding; dat zijn de verschaffers van het risicodragende vermogen en eventueel andere deelgerechtigden in de winst;

- degenen die in hoofdzaak belang hebben bij de solvabiliteit van de bedrijfshuishouding (waaraan inherent is een minimum-vermogenspositie en een minimumrentabiliteit), bestaande uit de overige vermogensverschaffers en eventuele andere geïnteresseerden,

alleen voor zover zij niet in staat zijn, zelf opdrachten aan de accountant te verstrekken.

De aandeelhouders in een naamloze vennootschap, die niet een machtspositie innemen, worden gewoonlijk tot het maatschappelijk verkeer gerekend. Weliswaar kunnen zij deelnemen aan de algemene vergadering van aandeelhouders (evenals de directie en het college van commissarissen een orgaan van de naamloze vennootschap, dat een opdracht aan een accountant kan verstrekken), maar buiten die vergadering hebben zij geen zeggenschap.

Wanneer opdrachtgever, gecontroleerde en belanghebbende één persoon zijn, 
is er sprake van een interne functie: de accountant is werkzaam in een huishouding ten behoeve van een orgaan van die huishouding.

Wanneer er scheiding is tussen belanghebbende en gecontroleerde, is er sprake van een externe functie: de accountant is werkzaam in een huishouding ten behoeve van buiten de huishouding staande personen.

Is de belanghebbende tevens opdrachtgever, dan is er een externe functie ten behoeve van een gesloten verkeer.

Is de gecontroleerde tevens opdrachtgever, dan is er een externe functie ten behoeve van het maatschappelijk verkeer. In deze functie treedt de accountant uitsluitend als controleur en niet als adviseur op.

De belanghebbende en de gecontroleerde hebben vaak van elkaar afwijkende belangen. De accountant die uiteraard fungeert ten behoeve van de belanghebbende, mag zich niet door het subjectieve oordeel van de gecontroleerde laten beinvloeden; hij moet dus functioneel onafhankelijk van de gecontroleerde zijn. Dit betekent dat de accountant in de externe functie ten behoeve van het maatschappelijk verkeer niet in dienstbetrekking bij de opdrachtgever (= gecontroleerde) mag zijn. In de overige gevallen (interne functie en externe functie ten behoeve van een gesloten verkeer) is er tegen een dienstbetrekking van de accountant bij de opdrachtgever geen bezwaar.

De openbare accountant kan alle accountantsfuncties vervullen. Hij kan dus optreden als controleur en adviseur ten behoeve van leidende organen van huishoudingen (interne functie), als controleur en adviseur ten behoeve van een gesloten verkeer (externe functie) en als controleur ten behoeve van het maatschappelijk verkeer (externe functie).

De accountant in dienstbetrekking bij een niet-accountant dient de functie van controleur ten behoeve van het maatschappelijk verkeer niet te vervullen. Hij kan optreden als controleur en adviseur ten behoeve van leidende organen van de huishouding waarin hij werkzaam is en ten behoeve van een eventueel daarbij behorend gesloten verkeer (interne en externe functie).

De accountant in dienst van een onderneming wordt meestal intern accountant genoemd. Hij kan echter ook een externe functie vervullen (bv. controle van geliëerde ondernemingen, kredietonderzoeken e.d.) .

De overheidsaccountants zijn werkzaam bij accountantsdiensten van het rijk, de provincies en de gemeenten en enkele bij de wet ingestelde colleges (verzekeringskamer, toezicht notarissen).

De meeste diensten hebben een interne en externe functie; zij houden zich bezig met algemene controles, controles met bijzonder doel en advieswerk bij afdelingen comptabiliteit, overheidsbedrijven en -diensten en gesubsidieerde instellingen; ook worden controles met bijzonder doel ingesteld bij particuliere ondernemingen.

De Rijksaccountantsdienst is een extern controlerend orgaan ten behoeve van een gesloten verkeer, i.c. de belastingdienst. De dienst houdt zich voornamelijk bezig met het instellen van controles met bijzonder doel. Dit doel is het vormen van een oordeel omtrent de aanvaardbaarheid van gedane aangiften of overlegde gegevens voor, de inkomsten- en vermogensbelasting, vennootschapsbelasting, omzetbelasting en invoerrechten, door ondernemingen of beoefenaren van vrije beroepen. Bijkomstig vinden onderzoeken plaats voor andere belastingen en voor andere overheidsinstanties (fraude-onderzoeken). 
De belanghebbende-opdrachtgever c.q. de werkgever zal zeggenschap hebben inzake de doelstelling van de taak van de accountant, uiteraard binnen de grenzen van redelijkheid en rationaliteit. De accountant zal als vakman zelf moeten bepalen op welke wijze de taak vaktechnisch moet worden uitgevoerd.

In de externe functie ten behoeve van het maatschappelijk verkeer moet de accountant functioneel onafhankelijk van de gecontroleerde zijn. Laatstgenoemde zal de opdracht tot controle verstrekken, maar op de taakbepaling mag hij geen invloed uitoefenen. De belanghebbenden in het verkeer vormen een ongeorganiseerde en niet te organiseren, steeds van samenstelling wisselende massa, die zich omtrent de taak van de accountant niet kan uitspreken. De enige mogelijkheid is nu dat de accountant zelf de doelstelling van zijn taak bepaalt. Hij doet dit dan als vertrouwensman van het maatschappelijk verkeer.

De belanghebbenden in het verkeer dienen te weten op welke wijze een bevoegd accountant te herkennen is. De accountant kan zich legitimeren door het gebruik van een wettelijk beschermde titel of bij gebreke hiervan door vermelding van het lidmaatschap van een te goeder naam en faam bekend staande vereniging. De belanghebbenden weten niets omtrent uiteenlopende capaciteiten en inzichten van verschillende accountants en zij kunnen dus geen onderscheid maken tussen verklaringen welke van verschillende accountants afkomstig zijn. Hieruit volgt dat alle verklaringen dezelfde betekenis moeten hebben en dat kan alleen als de controleprogramma's van verschillende accountants voor soortgelijke onderzoeken een gelijk waardige inhoud hebben, m.a.w. als hiervoor een objectieve norm bestaat. Uit deze eist vloeit voort, dat noch de opdrachtgever noch zelfs de individuele accountant hierop een subjectieve invloed mag uitoefenen. Het is duidelijk dat de norm voor een controleprogramma alleen kan worden bepaald door de gezamenlijke accountants omdat zij bij uitsluiting deskundig zijn op dit terrein. Deze norm ontstaat door onderling beraad en uitwisseling van vaktechnische gegevens. De accountants zullen, rekening houdend met stemmen uit het verkeer die tot hen doordringen, de omvang van de behoeften moeten schatten en de daarbij passende omvang van de controlewerkzaamheden moeten bepalen. De norm kan al of niet worden vastgelegd in de literatuur, in opsommingen van controlemaatregelen per onderneming of per object (standaards, procedures), in reglementaire bepalingen e.d.

Men kan de vraag stellen of de fiscus behoort tot het maatschappelijk verkeer, m.a.w. of de openbare accountant ook vertrouwensman is van de fiscus. Deze vraag dient ontkennend te worden beantwoord. De fiscus heeft een eigen gesloten verkeer, kan controle-opdrachten verstrekken en heeft zelfs een eigen controledienst, zodat er aan een vertrouwensman geen behoef te is. Wel is het natuurlijk zo, dat de verklaring van de openbare accountant geldt tegenover een ieder, ook buiten het verkeer, mits men zich ervan bewust is dat de verklaring is opgemaakt overeenkomstig de normen van het verkeer. Een fiscaal ambtenaar kan dus een door een openbare accountant ondertekende commerciële jaarrekening wel gebruiken bij de beoordeling van een aangifte, maar hij kan er zonder meer geen conclusie uit trekken ten aanzien van de juistheid van die aangifte. Daarvoor zou een gecertificeerde fiscale jaarrekening nodig zijn en dit is geen gebruikelijke figuur.

Ondernemers en beoefenaars van vrije beroepen zijn wettelijk verplicht inzage te verlenen van boeken en bescheiden tot staving van de aangifte. Het is uiteraard 
niet mogelijk en ook niet nodig doorlopend alle aangiften van alle belastingplichtigen te controleren. De leiding van de belastingdienst bepaalt in beginsel de omvang van het controle-apparaat, de diepgang van de controle en de controlefrequentie.

Het komt wel voor, dat bepaalde onderdelen van de administratie aan wettelijke voorschriften moeten voldoen. Ook worden wel voorwaarden van administratieve aard gesteld bij het verlenen van bepaalde vergunningen. Maar in het algemeen kan men wel zeggen dat de ondernemingen vrij zijn in hun administratieve organisatie. $\mathrm{Zij}$ behoeven slechts ter inzage te geven wat zij hebben, ook al is dit onvolledig en van slechte $k$ waliteit. De openbare accountant kan in een overeenkomstig geval de opdracht teruggeven, de fiscale controleur kan dit natuurlijk niet. Daartegenover is de fiscus op enkele punten in het voordeel, met name wat betreft het gebruik maken van de gegevens van de ene zaak bij de controle op de andere (bedrijfsvergelijking, renseignementen, verplichte opgaven e.d.).

Van de rijksaccountant wordt een oordeel verwacht omtrent de aanvaardbaarheid van de belastingaangifte, eventueel vergezeld van een opsomming van de correcties welke hij nodig acht.

Voor de inkomsten- en vermogensbelasting en voor de vennootschapsbelasting zijn de hoofdobjecten van onderzoek de winst en het eigen vermogen van de onderneming.

Daar de belastingwetten eigen waarderingsregels kennen dient de aangifte gebaseerd te zijn op een fiscale jaarrekening. Deze kan gelijk zijn aan de commerciële jaarrekening of daarvan af wijken. De afwijkingen dienen te worden geanalyseerd en onderzocht; daarna kan het onderzoek worden gericht op de commerciële jaarrekening en de daaraan ten grondslag liggende administratie. De commerciële jaarrekening moet worden geanalyseerd; de componenten daarvan, inclusief de eventuele afwijkingen dienen te worden getoetst aan de belastingvoorschriften. $\mathrm{Om}$ tot een gefundeerd oordeel te komen zal de accountant een indruk moeten krijgen omtrent de betrouwbaarheid van de administratie. Welke maatregelen hij hiervoor zal moeten nemen, zal van de omstandigheden in elk bijzonder geval afhangen. Vast staat dat hij ook bij de meest uitgebreide maatregelen in het algemeen niet tot volledige zekerheid zal kunnen komen, omdat hij geen zeggenschap heeft over de administratieve organisatie, geen gebruik kan maken van de interne controle, steeds achteraf moet controleren en geen tussentijdse waarnemingen kan doen.

De regel van de controleleer, dat bij onderzoeken met bijzonder doel rekening moet worden gehouden met het subjectieve belang van de gecontroleerde en de hieruit voortvloeiende tendens ten aanzien van de voorstelling van zaken, dient ook hier te worden toegepast. Het belang van de belastingplichtige, zo weinig mogelijk belasting te betalen, leidt tot de tendens het inkomen en vermogen zo laag mogelijk voor te stellen. Dit kan geschieden door verlaging van baten en verhoging van lasten (c.q. opvoering van fictieve lasten) resp. verlaging van activa en verhoging van passiva (c.q. opvoering van fictieve passiva). De rijksaccountant zal bij het opstellen van zijn controleprogramma hiermee rekening houden en dus in beginsel de baten en de activa negatief, de lasten en de passiva positief controleren.

Voor de omzetbelasting is de omzet hoofdobject van onderzoek. Deze zal in beginsel negatief moeten worden gecontroleerd aan de hand van de administratie van de goederenbeweging. Ook de kostenrekeningen (verband met inkopen, moge- 
lijke verkopen) en de rekeningen van de bedrijfsmiddelen (verkopen) zullen moeten worden bezien. Natuurlijk is het ook nodig, een oordeel te vormen omtrent de betrouwbaarheid van de administratie. Dit kan desgewenst geschieden bij het onderzoek voor de inkomsten- of vennootschapsbelasting, mits het tijdsverloop tussen beide onderzoeken niet te groot is.

Specifiek voor de omzetbelasting is het onderzoek naar de juiste tariefstoepassing. Is de aannemelijkheid van de totaalomzet eenmaal gebleken, dan kan de omzet in de hoogste tariefgroep als juist worden aangenomen en kan de detailcontrole worden beperkt tot de lagere tariefgroepen.

De rijksaccountant kan bij zijn werk in aanraking komen met interne en externe functionarissen van de onderneming.

Onder de interne functionarissen neemt de interne accountant een bijzondere plaats in. Aangenomen dat hij registeraccountant is, is hij onderworpen aan de reglementen van het Nederlands Instituut van Registeraccountants. De rijksaccountant zal op zijn werk kunnen steunen op overeenkomstige manier als de openbare accountant dit doet, hoewel dit niet reglementair geregeld is.

De externe functionarissen zijn de belastingadviseur, de openbare accountantcontroleur en de administratieve dienstverlener. Ofschoon hun functies in één persoon verenigd kunnen zijn, dienen deze ter bepaling van het in te nemen standpunt afzonderlijk te worden beschouwd.

De belastingadviseur gaat uit van de juistheid van de commerciële jaarrekening; hij analyseert deze voor zover nodig en gaat na of wijzigingen moeten worden aangebracht in verband met de belastingvoorschriften. Daarna stelt hij fiscale jaarstukken samen en verzorgt de aangifte. Voor zover er keuzemogelijkheid is zal hij de voor zijn cliënt voordeligste oplossing kiezen. Zo nodig voert hij besprekingen met de inspecteur, stelt bezwaar- en beroepschriften op en behandelt deze bij de bevoegde instanties.

De openbare accountant heeft als zodanig geen bemoeienis met de belastingaangifte. Bij de grote onderneming geeft hij een verklaring bij de jaarrekening af, bestemd voor het maatschappelijk verkeer. Bij de kleine onderneming kan hij ten hoogste tot een z.g. non-opinion-verklaring komen, omdat de interne organisatie hem geen voldoende steun kan geven bij de volledigheidscontrole.

De administratieve dienstverlener, die meestal slechts bij de kleine onderneming optreedt, verricht die werkzaamheden met betrekking tot de administratie en de jaarrekening, welke niet door personeel van de onderneming kunnen worden verricht. Zijn functie heeft een intern karakter. Indien hij controlemaatregelen toepast kunnen deze niet leiden tot een goedkeurende verklaring bij de jaarrekening omdat de verklaring voor een belangrijk deel betrekking zou hebben op door hemzelf verrichte administratieve werkzaamheden.

De vraag is nu of en in hoeverre de rijksaccountant kan steunen op het werk van genoemde functionarissen.

De rijksaccountant heeft tot taak, na te gaan of de belastingwetten juist zijn toegepast. Hij zal zich hierover een eigen oordeel moeten vormen en kan dus niet afgaan op het min of meer subjectieve oordeel van de belastingadviseur. In beginsel zal hij dus het werk van de belastingadviseur moeten controleren, waarbij het van de omstandigheden zal afhangen of dit integraal dan wel steekproefsgewijs zal moeten plaatsvinden . 
De rijksaccountant kan de goedkeurende verklaring van de openbaar accountant bij de grote onderneming zonder meer aanvaarden en hij kan dus bij zijn analyse van de commerciële jaarrekening uitgaan van de juistheid daarvan binnen de normen geldend in het maatschappelijk verkeer.

De non-opinion-verklaring van de openbare accountant bij de kleine onderneming geeft niet voldoende zekerheid omtrent de volledigheid van de verantwoording. Er zal dus een aanvullend onderzoek door de rijksaccountant nodig zijn, waarbij in het kader van de fiscale winst- en vermogensberekening de nadruk zal vallen op de negatieve controle van de baten en van de activa. Hierbij kunnen de reeds vermelde mogelijkheden van bedrijfsvergelijking e.d. worden benut.

Op het werk van de administratieve dienstverlener kan de rijksaccountant in beginsel niet méér steunen dan op het werk van de interne boekhouder omdat beiden een interne functie ten behoeve van de belastingplichtige vervullen; alleen door accountantscontrole (zo deze in beginsel mogelijk is) kan zekerheid omtrent het door hen verrichte werk worden verkregen.

Tenslotte kan worden opgemerkt, dat zowel de rijksaccountant als de genoemde interne functionarissen optreden bij verschillende ondernemingen. De rijksaccountant kan dus zijn oordeel omtrent de mate waarin hij op het werk van deze functionarissen in een bepaalde onderneming kan steunen, mede baseren op de ervaringen van hem - en eventueel ook van zijn collega's - bij andere ondernemingen opgedaan. 